\title{
Analysis of Historic Pavement and Bridge Conditions and Alternative Funding Levels for the Michigan Department of Transportation
}

\author{
William Robert ${ }^{1}$, Kirk Steudle ${ }^{2}$ and Polly Kent ${ }^{2}$ \\ 1. Spy Pond Partners, LLC, Arlington 02476, USA \\ 2. Michigan Department of Transportation , Lansing 48933, USA
}

\begin{abstract}
In 1997, MDOT (Michigan Department of Transportation) established an ambitious set of condition targets for its pavements and bridges and the department received increased revenue from a 4-cent-per-gallon increase in the state motor fuels tax to help meet its targets. However, over time, actual revenue was less than what was initially estimated as needed and actual conditions fell short of the target levels. In 2013, MDOT performed an analysis of historic conditions to determine what additional fuel tax revenues would have been required beginning in 1997 to replace bond revenues used to fund pavement and bridge projects from 1997 to 2012 and enable MDOT to meet its condition targets. The analysis concluded that, in addition to the actual increase of 4 cents per gallon, a fuel tax increase of another 10 cents per gallon would have been required in 1997 to replace bond revenue used for pavement and bridges and allow MDOT to meet its condition targets. The analysis results were used to help inform the discussion of Michigan's targets asset conditions and funding and demonstrate application of MDOT's pavement and bridge management systems for performing historic analyses.
\end{abstract}

Key words: Transportation asset management, transportation finance, performance measures, pavement management, bridge management.

\section{Introduction}

MDOT (Michigan Department of Transportation) is responsible for maintaining approximately 9,650 miles of state trunkline highways and over 4,400 bridges. The department is responsible for approximately $8 \%$ of Michigan's roadway network, but MDOT's portion of the network carries approximately $51 \%$ of total statewide traffic and accounts for $74 \%$ of the statewide bridge deck area [1].

Transportation asset management, defined in Michigan law (Public Act 51 Section 247.659a) as "an ongoing process of maintaining, upgrading and operating physical assets cost-effectively, based on a continuous physical inventory and condition

Corresponding author: William Robert, B.Sc., vice president, research fields: transportation asset management and state of good repair. E-mail: wrobert@spypondpartners.com. assessment” has been a priority for MDOT since the 1990s. In 1992, MDOT developed the Michigan Capital Preventive Maintenance Program to preserve pavement and bridge structures, delay future deterioration and improve overall conditions cost-effectively and efficiently [2]. But without additional funding, by 1997, asset conditions deteriorated to the point that approximately $40 \%$ of the state network was rated as being in poor condition and there was significant public concern over the poor condition of the state's roads [3]. In part based on analyses performed by MDOT, the state legislature approved a 4-cent increase in the state motor fuels tax, from 15 to 19 cents per gallon that took effect midway through 1997. MDOT made a series of significant additional changes at this time, including setting performance targets for pavements and bridges and creating an annually-updated 5-year program 
document. In 2003, the department made a further change, shifting away from system expansion to chiefly focus on preservation.

MDOT worked with the state transportation commission to establish performance targets to help direct investment of the additional funds raised by the tax increase. Specifically, the department set a target of having $85 \%$ of non-freeway trunkline pavements and $95 \%$ of freeway pavements in good or fair condition. MDOT's goal was to achieve these targets within 10 years by 2007. Subsequently, the two targets were combined, so the overall goal was to have $90 \%$ of the MDOT network in good or fair condition, though the analysis described here retains the original two-tiered targets. A pavement section is classified in being in good or fair condition if it has an RSL (remaining service life) of 3 or more years. RSL is determined based on a measure termed the distress index, calculated as described in Ref. [4].

With respect to bridge conditions, a bridge is classified as being in good or fair condition if it is not structurally deficient. That is, it should have NBI (national bridge inventory) deck, superstructure and substructure condition ratings of 5 or greater as detailed in Ref. [5].

Following the 1997 tax increase, pavement and bridge conditions were steadily improved. However, the revenue increase was somewhat less than that initially projected to reach the targets and over time revenues fell below initial projections, largely due to poor economic conditions and increasing fuel efficiency. Consequently, MDOT increased its use of bonds to sustain its funding. Proctor et al. [6] detail the use of bond funding in the recent report The Road Not Taken-Michigan's Highway Funding Decisions: Lessons from the Past and Implications for the Future, concluding the use of bonds which allowed MDOT to improve its pavement and bridge conditions through 2007, but left MDOT with a significant debt, as well as debt payments of over $\$ 100$ million annually for bonds issued to fund pavement and bridge-related preservation. A combination of additional preservation bonding and ARRA (American Recovery and Reinvestment Act) funds allowed MDOT to further improve pavement and bridge condition until 2012.

Based on 2012 funding levels, MDOT pavement and bridge conditions were predicted to decline over time, as inflation and debt payments continued to erode the department's budget. Fig. 1, reproduced from Ref. [1], shows historic and predicted future pavement conditions for freeways made using actual data through 2011 and projections based on current funding levels for subsequent years. Fig. 2 shows historic and predicted future conditions for freeway bridges at current funding levels. The projections shown in these figures were made using the RQFS (roadway quality forecasting system) and BCFS (bridge condition forecasting system) described in the next section.

Both figures illustrate improving conditions in the late 1990s and early 2000s and a projected decline in conditions in the future. The basic trends are similar for non-freeways, but MDOT is exceeding the target level of $85 \%$ good or fair for non-freeway pavements and bridges. The figures serve to illustrate two key concerns for MDOT. First, in the area of freeway pavements, MDOT has not yet reached its condition target and is now moving away from rather than towards the target condition level. Second, moving forward at 2012 funding levels, asset conditions are projected to decline to levels not experienced by Michigan road users since the late 1990s.

To support deliberations on future funding, in 2013, MDOT performed an analysis to obtain insights on how conditions had varied over time, and what changes would have been needed in 1997 to enable MDOT to achieve its condition targets. Specifically, the analysis was conducted using MDOT's pavement and bridge management systems to determine the additional fuel tax revenues that would have been required beginning in 1997 to replace bond revenues used to fund pavement and bridge projects from 1997 


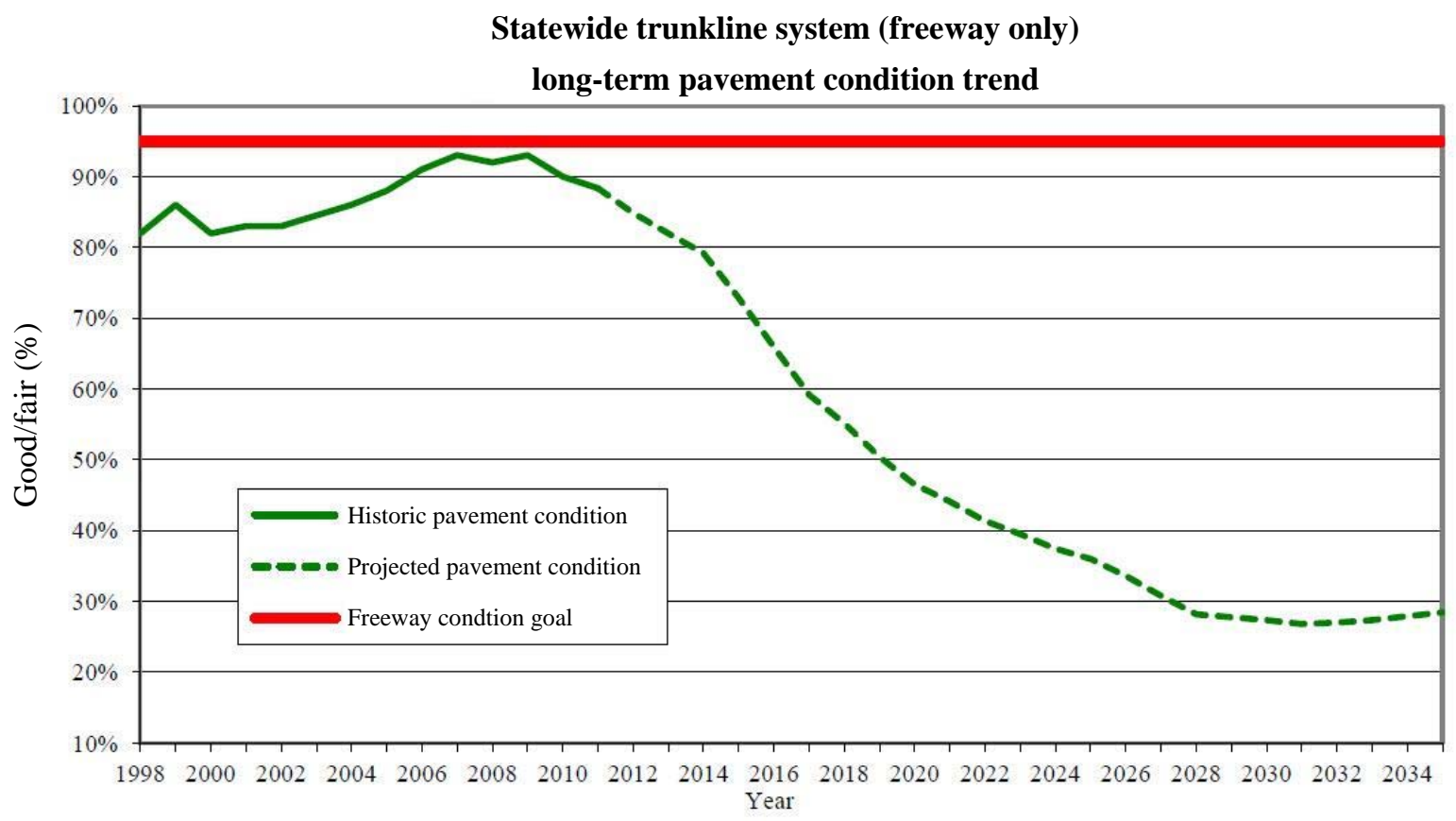

Fig. 1 MDOT freeway pavement conditions.

Source: MDOT [1].

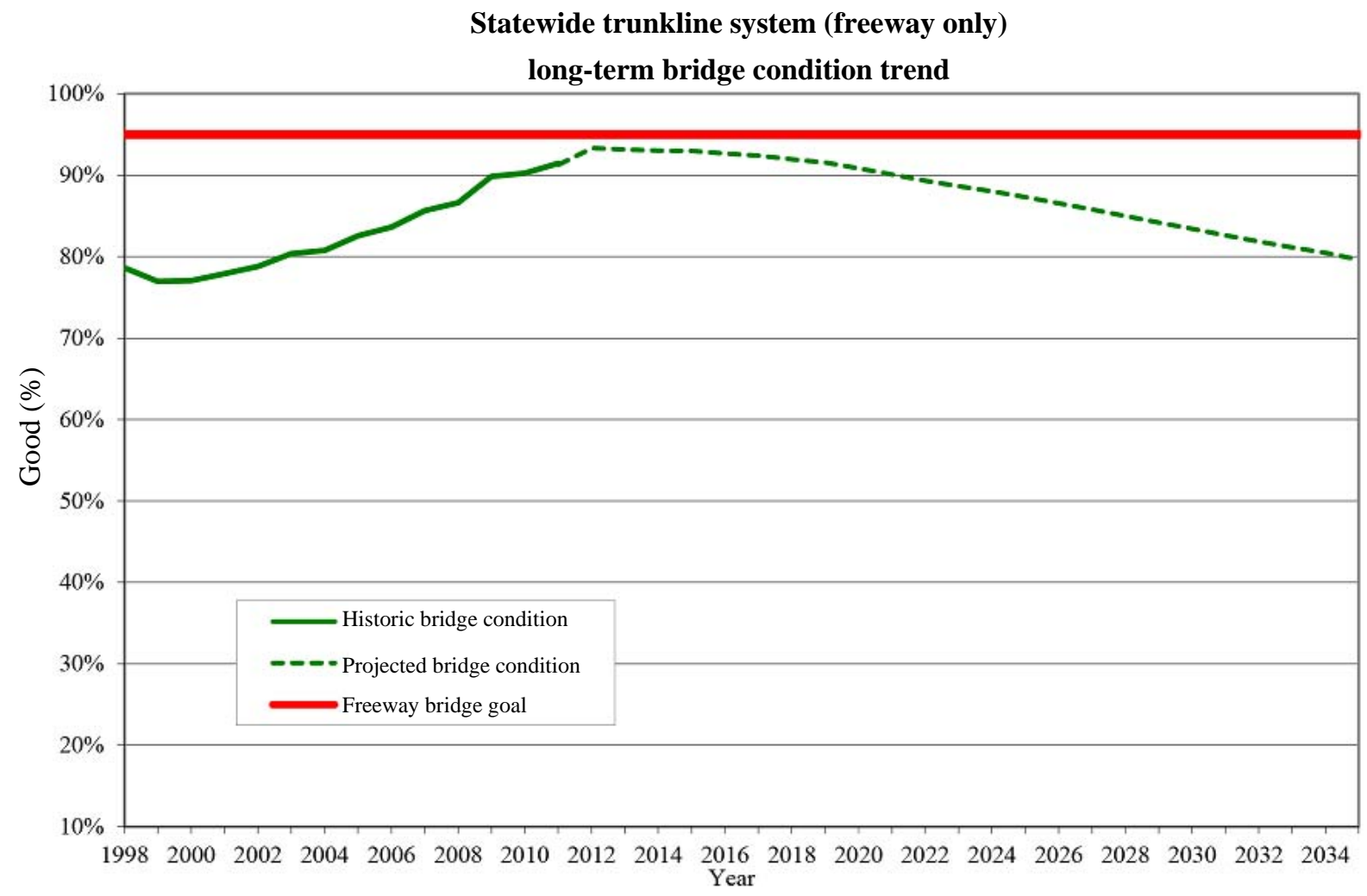

Fig. 2 MDOT freeway bridge conditions.

Source: MDOT [1]. 
to 2012 and enable MDOT to meet its target pavement and condition levels. The following sections detail the analysis approach, results and conclusions.

\section{Analysis Approach}

Determining the additional fuel tax revenues that would have been required by MDOT to achieve its condition targets involved four primary analysis steps, described further in the following subsections:

(1) projecting fuel tax revenue from a given tax increase;

(2) calculating bond revenue and repayment costs;

(3) predicting pavement and bridge conditions given a specified funding level;

(4) combining the revenue, bond and condition calculations.

\subsection{Projecting Fuel Tax Revenue}

Revenue projections were developed using data on the revenues and split of revenues from the actual 4-cent increase, the gas price and estimated fuel price elasticity of demand. Regarding the previous increase, MDOT staff first tabulated the total revenue from the increase received by the MTF (Michigan Transportation Fund). The revenue from the 4-cent increase in the fuel tax can be scaled to predict revenue that would have been realized from a further increase. However, the estimate needs to be adjusted for the price elasticity of demand. That is, the estimate needs to account for the fact that as the price of a good increases, the demand for that good tends to fall. A number of estimates of the fuel price elasticity of demand are available in the literature. For instance, Wong [7] reviews several studies of fuel price elasticity with estimates ranging from -0.1 to -1.1 , with demand being more inelastic in the short term. Poor [8] reviews over 30 sources on or related to fuel price elasticity and notes that the value the WSDOT (Washington State Department of Transportation) uses for this parameter is -0.2 . For the purpose of this analysis, the WSDOT default of -0.2 was used, as this value is well within the range reported by Wong [7] and Poor [8]. The interpretation of this value is that, for each percentage increase in the price of gasoline, demand drops by $0.2 \%$. Note that a sensitivity analysis was performed, testing the effects of varying elasticity, but changing the value from -0.2 to any other value in the range reported by Wong [7] and Poor [8] did not significantly impact the results presented here (that is, changing the elasticity within this range resulted in a change to the required gas tax of less than half a penny).

In order to calculate the impact of elasticity on tax revenues, it is necessary to estimate the price of fuel. Average fuel prices were obtained from US Energy Information Administration data (available at http://www.eia.gov/). For recent years, a midwestern price estimate has been available, but the average US price was used, as the midwestern estimate is not available for the full analysis period and is in any case highly correlated with the US value.

Together, the parameters above support the calculation of MTF revenues from an additional increase in the fuel tax from 1997 to 2012. However, further calculations are required to determine the share of funds that would have been used for MDOT pavement and bridge preservation projects. MTF funds are divided between MDOT and Michigan counties and cities. From 1997 to 2004, MDOT received approximately $54 \%$ of the MTF total for the increased revenues. This figure declined to $48 \%$ in 2005 and approximately 42\% from 2006 to 2012 [6]. Of the MDOT total, MDOT staff calculated that approximately $68 \%$ of the funds from the state fuel tax increase was used for non-capital uses not eligible for federal aid such as routine maintenance, administration and debt servicing. The remaining 32\% was used for the capital program, with $40 \%$ of the capital program allocation used for pavement preservation and $17 \%$ for bridge preservation. For projecting the impact of additional funding, it was 
projected that the same splits would apply, though no additional funding would be required for non-capital uses. Thus, the analysis assumed that for each additional dollar of state fuel tax revenue received by MTF, approximately 17 to 22 cents would be used to match federal aid for pavement preservation, while 7 to 9 cents would be used to match federal aid for bridge preservation.

Table 1 illustrates the calculations for a hypothetical and additional increase of 4 cents per gallon. The table shows the average price of gasoline by year, actual MTF revenue from the previous increase, additional tax estimated accounting for elasticity and predicted additional MDOT capital revenue (total, pavement and bridge). All values are in current dollars. In this example, an additional 4-cent increase is projected to yield somewhat less additional revenue than that projected for the previous increase (95\% to 99\%, depending on the year). After 1997 (the year the tax was implemented), the additional funds were expected to equate to $\$ 29$ million to $\$ 41$ million of additional funds for pavement and $\$ 13$ million to \$18 million additional for bridge, with revenues declining significantly after 2004. This decline was attributed to increasing fuel efficiency and reduction in VMT (vehicle miles traveled) during the 2007-2009 recession [6].

\subsection{Calculating Bond Revenue}

MDOT staff prepared estimates of the revenues received from bonds from 1997 to 2012 for pavement and bridge preservation and the cost of payments of principal and interest on those bonds made over the period of analysis. Table 2 summarizes the bonds issued and subsequent repayment costs in current year dollars, including only the portion of the bonds used for pavement and bridge preservation. The table shows that, over the period from 1997 to 2012, MDOT used \$1.49 billion of bond funding (in current dollars) for pavement and bridge preservation, and over this same period, paid approximately \$571 million in interest and principal on those bonds. Most bonds were issued from 2001 to 2007 and the bulk of repayment costs was incurred from 2010 to 2012. After 2007, MDOT neared the limit that it could borrow using future federal-aid highway funds and realized that it was infeasible to continue to finance its capital program relying heavily on bonds [9].

Table 1 Predicted revenue from an additional 4-cent fuel tax (current dollars).

\begin{tabular}{|c|c|c|c|c|c|c|}
\hline \multirow{2}{*}{ Year } & \multirow{2}{*}{$\begin{array}{l}\text { Fuel price } \\
\text { (\$/gallon) }\end{array}$} & \multicolumn{2}{|c|}{ Michigan Transportation Fund revenue (\$M) } & \multicolumn{3}{|c|}{ Projected MDOT capital revenue from additional tax (\$M) } \\
\hline & & Previous increase & Projected from additional tax & Total & Pavement only & Bridge only \\
\hline 1997 & 1.19 & 32.3 & 31.1 & 16.9 & 6.7 & 2.9 \\
\hline 1998 & 1.02 & 190.2 & 181.6 & 98.6 & 39.4 & 17.1 \\
\hline 1999 & 1.12 & 196.0 & 187.9 & 101.9 & 40.7 & 17.7 \\
\hline 2000 & 1.46 & 194.1 & 188.0 & 102.4 & 40.9 & 17.7 \\
\hline 2001 & 1.38 & 196.5 & 190.0 & 102.9 & 41.1 & 17.8 \\
\hline 2002 & 1.31 & 197.7 & 190.7 & 103.7 & 41.4 & 18.0 \\
\hline 2003 & 1.52 & 197.0 & 191.0 & 103.7 & 41.4 & 18.0 \\
\hline 2004 & 1.81 & 196.2 & 191.3 & 103.8 & 41.4 & 18.0 \\
\hline 2005 & 2.24 & 194.2 & 190.2 & 91.5 & 36.6 & 15.9 \\
\hline 2006 & 2.53 & 190.8 & 187.3 & 78.4 & 31.3 & 13.6 \\
\hline 2007 & 2.77 & 186.0 & 182.9 & 76.5 & 30.6 & 13.3 \\
\hline 2008 & 3.21 & 178.7 & 176.1 & 73.7 & 29.4 & 12.8 \\
\hline 2009 & 2.31 & 178.1 & 174.6 & 73.0 & 29.1 & 12.6 \\
\hline 2010 & 2.74 & 177.2 & 174.2 & 72.9 & 29.1 & 12.6 \\
\hline 2011 & 3.48 & 175.1 & 172.8 & 72.3 & 28.9 & 12.5 \\
\hline 2012 & 3.55 & 172.4 & 170.1 & 71.2 & 28.4 & 12.3 \\
\hline Total & - & $2,852.5$ & $2,779.8$ & $1,343.4$ & 536.4 & 232.8 \\
\hline
\end{tabular}


Table 2 Use of bonds for pavement and bridge preservation (current dollars).

\begin{tabular}{|c|c|c|c|c|c|c|}
\hline \multirow{2}{*}{ Year } & \multicolumn{3}{|c|}{ Bonds issued (\$M) } & \multicolumn{3}{|c|}{ Repayment costs (\$M) } \\
\hline & Pavement & Bridge & Total & Pavement & Bridge & Total \\
\hline 1997 & 0.0 & 0.0 & 0.0 & 0.0 & 0.0 & 0.0 \\
\hline 1998 & 0.0 & 0.0 & 0.0 & 0.0 & 0.0 & 0.0 \\
\hline 1999 & 0.0 & 0.0 & 0.0 & 0.0 & 0.0 & 0.0 \\
\hline 2000 & 0.0 & 0.0 & 0.0 & 0.0 & 0.0 & 0.0 \\
\hline 2001 & 198.4 & 0.6 & 199.0 & 0.0 & 0.0 & 0.0 \\
\hline 2002 & 174.7 & 9.3 & 184.0 & 11.9 & 0.3 & 12.2 \\
\hline 2003 & 17.3 & 0.0 & 17.3 & 20.9 & 0.4 & 21.3 \\
\hline 2004 & 165.9 & 6.3 & 172.2 & 20.9 & 0.4 & 21.3 \\
\hline 2005 & 75.6 & 0.0 & 75.6 & 22.3 & 0.5 & 22.8 \\
\hline 2006 & 321.9 & 6.9 & 328.7 & 13.4 & 0.3 & 13.7 \\
\hline 2007 & 296.6 & 0.3 & 296.9 & 21.7 & 0.5 & 22.1 \\
\hline 2008 & 39.7 & 0.0 & 39.7 & 71.8 & 1.5 & 73.3 \\
\hline 2009 & 92.4 & 0.0 & 92.4 & 74.2 & 1.6 & 75.8 \\
\hline 2010 & 63.9 & 1.3 & 65.2 & 103.3 & 2.2 & 105.5 \\
\hline 2011 & 0.0 & 0.0 & 0.0 & 98.7 & 2.1 & 100.8 \\
\hline 2012 & 14.7 & 6.5 & 21.2 & 100.4 & 2.1 & 102.6 \\
\hline Total & $1,461.0$ & 31.2 & $1,492.2$ & 559.5 & 12.0 & 571.5 \\
\hline
\end{tabular}

\subsection{Predicting Pavement and Bridge Conditions}

The MDOT management systems RQFS and BCFS were used to predict the pavement and bridge conditions that would result from a variety of different budgets. Both systems were designed to predict future conditions and costs, rather than to perform a "back casting" analysis. To support the analysis, it was thus necessary to adjust results generated by the systems. Specifically, each system was used to predict the budget required to reproduce the conditions observed in 2012, starting with the 1997 conditions. A scaling factor was then derived from this exercise, such that the systems correctly reproduced historic conditions. Also, the systems were run each for a set of scenarios and a set of best-fit models were derived for predicting conditions given an assumed budget. These models are detailed in Tables 3 and 4.

RQFS is a strategy analysis tool developed and used by MDOT to project results of pavement rehabilitation policies. MDOT has documented the basic modeling approach of RQFS previously $[3,10]$. The primary performance measure in the system is RSL, calculated based on pavement distress data. The system is run with a given rehabilitation policy or "mix of fixes". The policy establishes thresholds for reactive maintenance, capital preventive maintenance, rehabilitation and reconstruction. The system predicts the treatments that will be performed at a network level given the policy and the resulting conditions for MDOT freeways and non-freeways. The system does not support specification of an overall budget. To test the impact of a given budget, it is necessary to adjust the model assumptions (e.g., amount of programmed

Table 3 Pavement best-fit models.

\begin{tabular}{lll}
\hline \multirow{2}{*}{ Parameter } & \multicolumn{2}{c}{ Value by model } \\
\cline { 2 - 3 } & 2007 & 2012 \\
\hline Freeway-m (slope) & $1.23 \mathrm{E}-10$ & $8.05 \mathrm{E}-11$ \\
Freeway-b (intercept) & 0.251 & 0.164 \\
Non-freeway-m (slope) & $1.31 \mathrm{E}-10$ & $8.02 \mathrm{E}-11$ \\
Non-freeway-b (intercept) & 0.118 & 0.067 \\
Calibration factor & 0.418 & 0.531 \\
\hline
\end{tabular}

Table 4 Bridge best-fit models.

\begin{tabular}{lll}
\hline \multirow{2}{*}{ Parameter } & \multicolumn{2}{c}{ Value by model } \\
\cline { 2 - 3 } & 2007 & 2012 \\
\hline Freeway-m (slope) & $1.38 \mathrm{E}-10$ & $6.26 \mathrm{E}-11$ \\
Freeway-b (intercept) & 0.574 & 0.741 \\
Non-freeway-m (slope) & $1.46 \mathrm{E}-10$ & $7.19 \mathrm{E}-11$ \\
Non-freeway-b (intercept) & 0.573 & 0.704 \\
Calibration factor & 1.055 & 1.082 \\
\hline
\end{tabular}


work and the rehabilitation policy). Also, although MDOT can run the system using data from a previous year, it is feasible to go back only as far as 1998. Also, funding for 1997 was largely unaffected by the gas tax increase, as the increase went into effect midway through the fiscal year. Thus, RQFS was run assuming 1997 funds were unchanged and any increased funding would be applied from 1998 to 2012.

Two scenarios were run in RQFS to test the impact of different budget assumptions. The total pavement budget from 1997 to 2012 for these scenarios ranged from $\$ 8$ billion to $\$ 9.5$ billion. In both scenarios, the pattern of funding was similar to that which actually occurred (excluding revenue from bonds), but the overall funding was varied. Fig. 3 shows the predicted percent good/fair for freeways and non-freeways by year for each scenario. The scenarios were characterized in terms of their overall funding in constant dollars (including 1997 expenditures not modeled by RQFS) and the resulting conditions for freeways and non-freeways in 2007 and 2012. A set of linear models were derived for predicting the freeway and non-freeway percent good/fair as a function of total funding. The table shows the slope (labeled as "b") and intercept (labeled as " $m$ ") for the best-fit models.

In deriving the models, a multiplier of the constant dollar budget was calculated such that the resulting linear models correctly predict the actual condition results given the actual constant dollar budget for pavement. Table 3 summarizes the resulting models. For instance, for freeway pavement in 2012, the slope of the resulting model is $8.05 \mathrm{E}-11$ and the intercept is 0.163 . Thus, given an $\$ 8$ billion total budget for pavement from 1997 to 2012, the model predicts the resulting percent good/fair for freeway would be $8.05 \mathrm{E}-11 \times 8.00 \mathrm{E}+9+0.163=0.808$, or approximately $81 \%$. Table 3 shows that, in deriving the models, relatively large multipliers were calculated for the budgets modeled by RQFS to match actual results: 0.418 for the 2007 model and 0.531 for the 2012 model, indicating that it was necessary to approximately halve the budget predicted by RQFS to match actual observations. These adjustments are

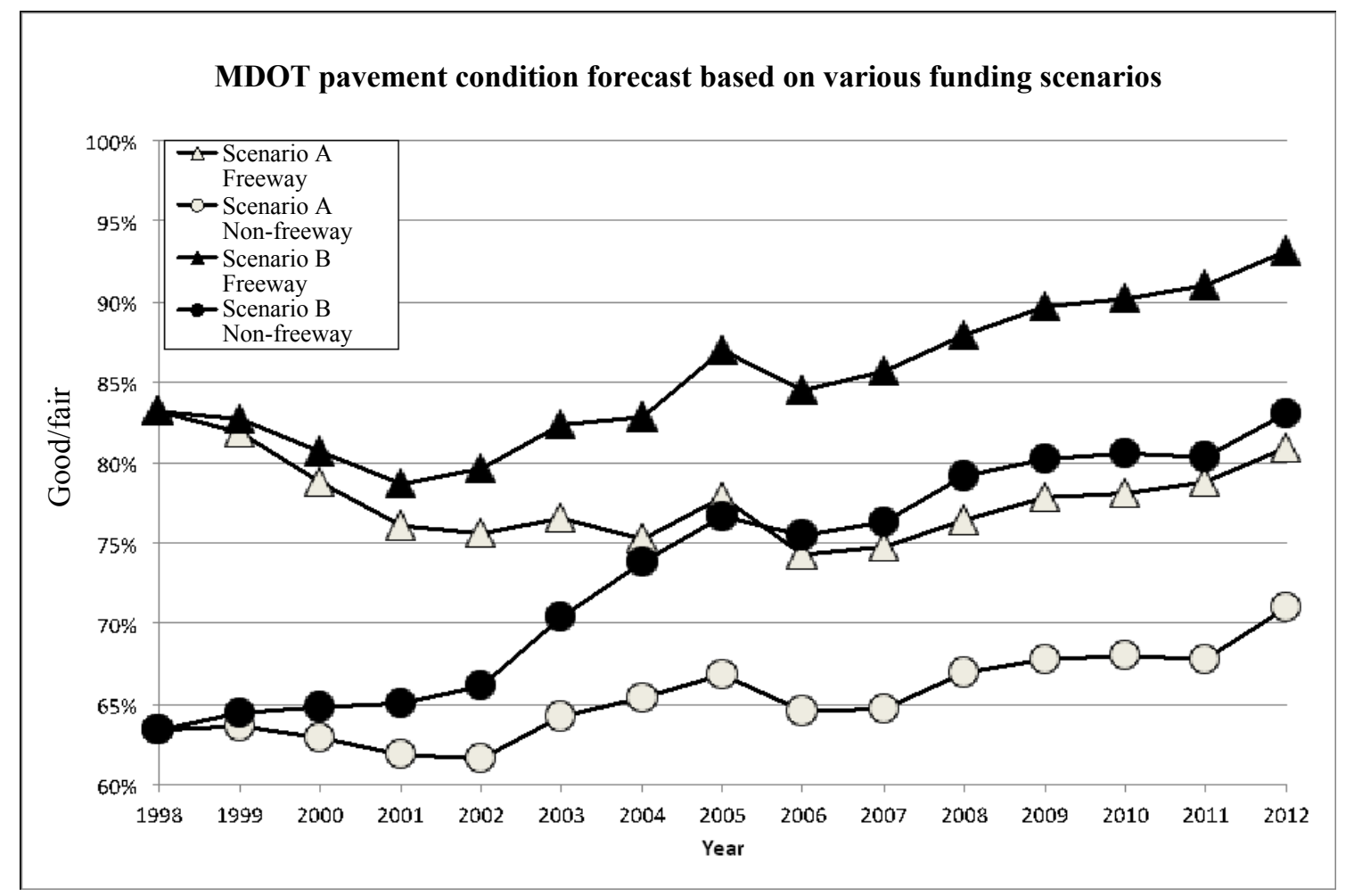

Fig. 3 ROFS projections for percent good/fair for selected scenarios. 
described further in Section 3.

A similar approach was used for predicting bridge conditions. MDOT uses BCFS for testing network-level bridge investment strategies. BCFS has two components. The first component calculates a transition probability matrix that predicts the likelihood of transition from one condition rating to another based on MDOT's historic NBI inspection data. The system uses the minimum of the deck, superstructure, substructure and culvert ratings for characterizing the condition rating of each bridge. The second component of the system simulates the effects of capital preventive maintenance, rehabilitation and replacement work, given an initial distribution of condition ratings, overall budget by year and split of the budget by the three categories of work. The system uses an average cost per bridge for each work type and incorporates a set of business rules for predicting the application of different treatments and their effects given a set of bridge condition ratings. Additional information on the system has been published by
MDOT and the FHWA (Federal Highway Administration) [3, 11].

Three scenarios were run in BCFS to test the impact of different budget assumptions. The total bridge budget from 1997 to 2012 for these scenarios ranged from $\$ 3.4$ billion to $\$ 4.1$ billion. For each scenario, it was necessary to run the system twice-from 1997 to 2006 and from 2007 to 2012, in the latter case using the predicted 2006 results as an input. Breaking the scenarios into two pieces was necessary as the system is designed for a 10-year analysis, but doing this allowed for specification of different deterioration rates for the two periods, consistent with the actual data. In the scenarios, the pattern of funding was similar to that which actually occurred, but the overall funding was varied. Fig. 4 shows the predicted percent good/fair for freeways and non-freeways by year for each scenario.

The approach described above for pavement was used to develop linear models for predicting bridge freeway and non-freeway percent good/fair in 2007

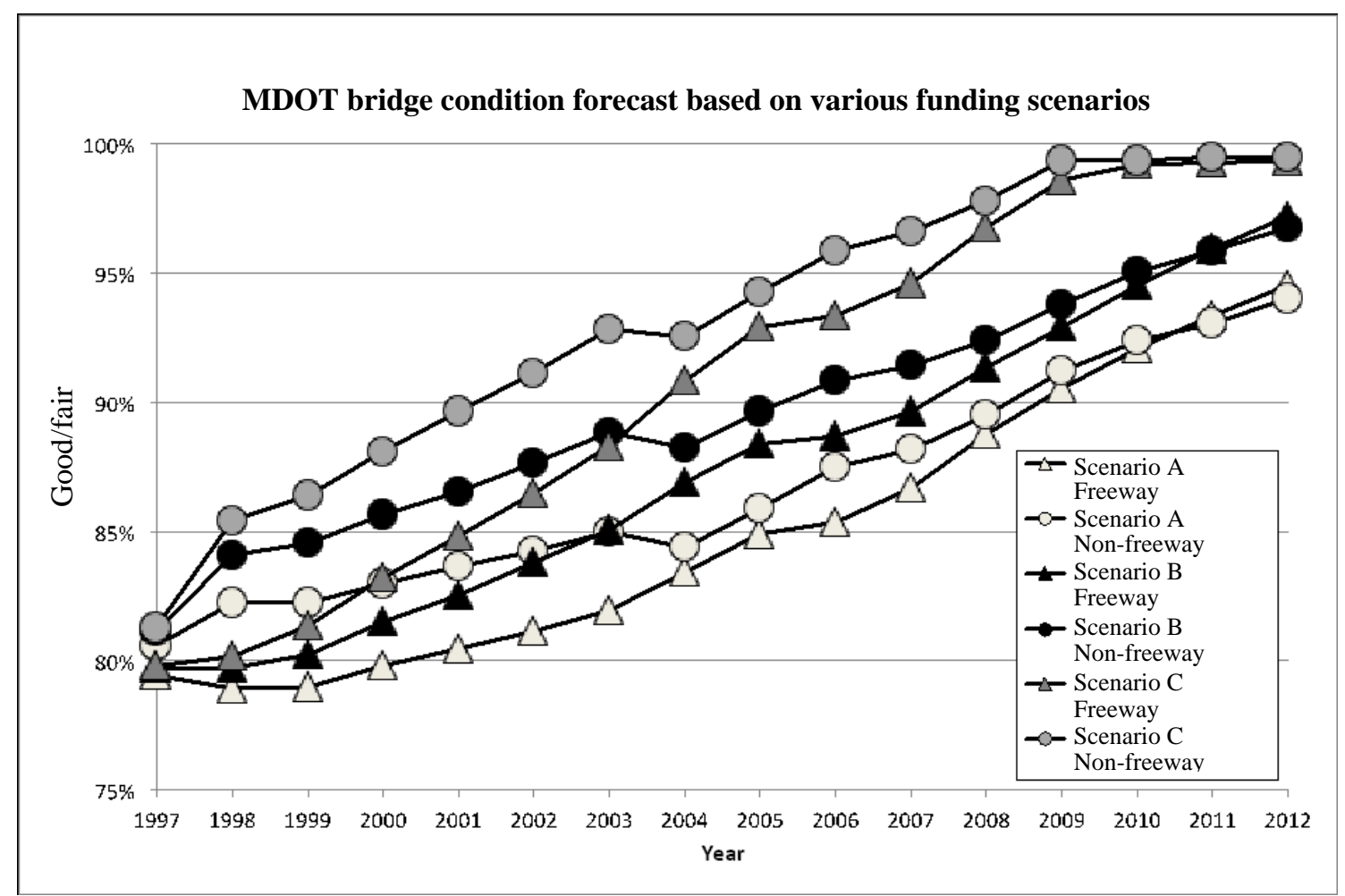

Fig. 4 BCFS Projections for Percent Good/Fair for Selected Scenarios. 
and 2012 given a total preservation budget expressed in constant dollars. Table 4 summarizes the resulting models. The table shows that a very modest adjustment was made to the budgets modeled by BCFS to match actual results, with calibration factors of 1.055 for the 2007 models and 1.082 for the 2012 models. These adjustments are described further in Section 3.

\subsection{Combining the Calculations}

The last step in the analysis was to combine the revenue, bond, pavement and bridge results. This was accomplished as follows:

Actual pavement and bridge preservation expenditures by year were adjusted to approximate the spending that would have occurred without bond revenues and repayment costs. In other words, revenues from bonds were subtracted from and repayment costs were added to actual preservation expenditures.

The fuel tax increase was specified, resulting in predicted additional revenue for pavement and bridge preservation. The resulting pavement and bridge funding (actual - bonds + additional funding) was calculated by year.
Total pavement and bridge funding was calculated, adjusting the year-by-year values for inflation. FHWA construction cost indices were used for this calculation. Note that FHWA's calculations of the NHCCI (national highway construction cost index) are published for years 2003 and forward. FHWA's composite construction index was used for prior years. This index predicted a $14.7 \%$ increase in prices from 1997 to 2003, versus a $9.6 \%$ increase for the BLS (Bureau of Labor Statistics) producer price index and a $14.6 \%$ increase in the consumer price index for this period. Fig. 5 shows the two FHWA indices and resulting value used for inflation adjustments.

Pavement and bridge conditions were projected given the resulting overall pavement and bridge budgets using the models specified in Tables 3 and 4 . Note that if the funding was sufficient for meeting the targets for one asset type, but not sufficient for meeting the targets for the other asset type, funds were "rebalanced", shifting the funds in excess of that required to meet MDOT's targets from one asset type to the other.

The process was repeated, testing different hypothetical tax increases to determine the tax increases that would have been required to: (1) replace funding

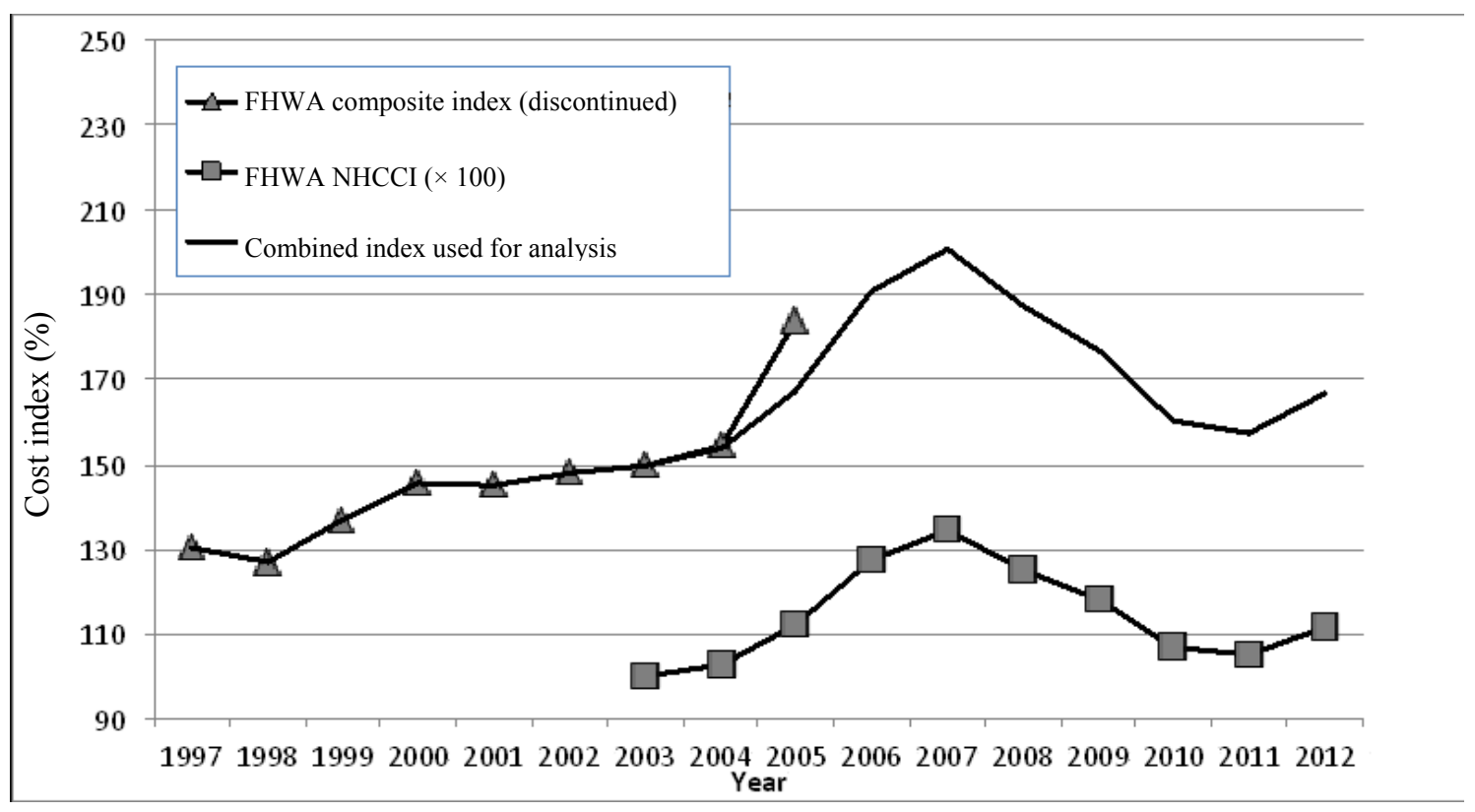

Fig. 5 Cost indices used for the analysis. 
from bonds; (2) both replace funding from bonds and achieve MDOT's pavement and bridge targets.

\section{Analysis Results}

Table 5 summarizes the results of the analysis. The table shows the total pavement and bridge budgets, and percent good/fair predicted by asset group for 2007 and 2012. Results are shown for four funding scenarios: actual funding; actual funding but without additional bond revenues; additional fuel tax increases of 5 cents; 10 cents without bonds. In the table, condition results are shaded where predicted to meet MDOT targets of $95 \%$ good/fair for freeways and $85 \%$ for non-freeways. Fig. 6 shows predicted conditions for 2012 graphically. Note the results are not highly sensitive to alternative assumptions regarding inflation or fuel price elasticity.

The table shows that MDOT met its goals for non-freeway conditions in both 2007 and 2012 and met its goals for freeway bridges in 2012. However, for freeway pavements, conditions fell slightly short of the goal in 2007 and since then have declined further. Without bonds, pavement conditions would have been significantly worse, with a drop of approximately $6 \%$ points for freeway pavements projected for 2012 and 18\% points for non-freeway pavements. An additional fuel tax of approximately 5 cents would have been required beginning in 1997 to generate the equivalent amount of revenue for pavement and bridge preservation as bonds did during the period from 1997 to 2012. However, an increase of 10 cents (in addition to the actual increase of 4 cents) would have been required to enable MDOT to meet its target condition levels, as illustrated in the last column of Table 5 and in Fig. 6.

One concern in analyzing the results was that a substantial adjustment was required to expenditures predicted by RQFS to match model results to actual observations. MDOT staff performed further analysis to better characterize this issue. Through this analysis, MDOT determined that two primary factors contributed to the discrepancy. One factor is that the projections for RQFS assume an average inflation rate of 5\% per year, consistent with MDOT experience. RQFS and BCFS runs were performed using 2012 costs, but in the case of RQFS, these costs were then inflated to account for predicted future inflation. A second factor is that RQFS assumes a somewhat different mix of fixes moving forward, with greater emphasis on rehabilitation and reconstruction, than MDOT actually used in the past. MDOT staff demonstrated that when RQFS is run with the actual mix of fixes used by MDOT, it closely approximates actual conditions. Based on the supplemental analysis, the approach of applying a multiplier to modeled expenditures was deemed to be reasonable for calibrating

Table 5 Summary results.

\begin{tabular}{llcccc}
\hline \multirow{2}{*}{ Description } & \multirow{2}{*}{ Asset group } & Actual funding & Actual-bonds & \multicolumn{2}{c}{ Actual-bonds + additional fuel tax } \\
\cline { 5 - 6 } & & & & 5 cents & 10 cents \\
\hline \multirow{2}{*}{$\begin{array}{l}\text { Total budget, 1997-2012 } \\
\text { (constant \$M) }\end{array}$} & Pavement & 8,573 & 7,710 & 8,738 & 9,705 \\
& Bridge & 3,289 & 3,257 & 3,257 & 3,306 \\
& Total & 11,862 & 10,967 & 11,996 & 13,012 \\
\hline \multirow{2}{*}{2007 good/fair (\%) } & Pavement-freeway & $93.0 \%$ & $83.9 \%$ & $90.5 \%$ & $96.6 \%$ \\
& Pavement-non-freeway & $91.2 \%$ & $74.4 \%$ & $81.5 \%$ & $87.9 \%$ \\
& Bridge-freeway & $87.9 \%$ & $87.6 \%$ & $90.8 \%$ & $94.5 \%$ \\
& Bridge-non-freeway & $89.4 \%$ & $89.2 \%$ & $92.6 \%$ & $96.5 \%$ \\
\hline \multirow{2}{*}{2012 good/fair (\%) } & Pavement-freeway & $85.4 \%$ & $78.5 \%$ & $86.7 \%$ & $94.5 \%$ \\
& Pavement-non-freeway & $87.1 \%$ & $68.5 \%$ & $76.7 \%$ & $84.5 \%$ \\
& Bridge-freeway & $94.6 \%$ & $94.5 \%$ & $94.5 \%$ & $94.8 \%$ \\
& Bridge-non-freeway & $94.2 \%$ & $93.8 \%$ & $93.8 \%$ & $94.2 \%$ \\
\hline
\end{tabular}




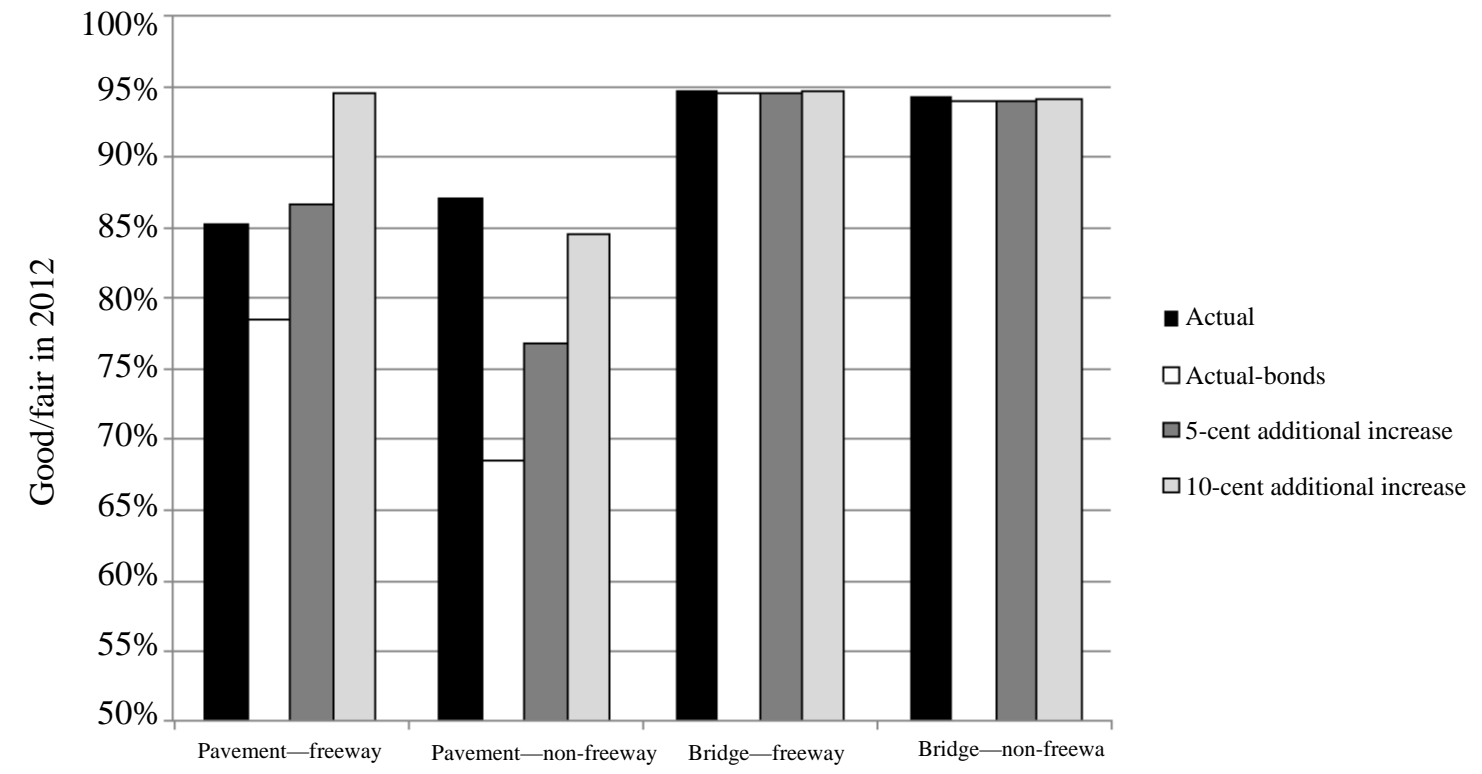

Fig. 6 Predicted percent good/fair in 2012 by asset group.

model to actual results, though further analysis may be warranted of RQFS modeling assumptions regarding future costs and treatments.

In contrast to the case of RQFS, for BCFS, very little adjustment was required to the system's projections. These stems from the fact BCFS projections were made in 2012 dollars without additional inflation assumed and from the fact that BCFS appears well-tailored for performing the sort of historic analysis were described here. Since BCFS fits a set of deterioration models based on observed data, it can be readily calibrated to work with historic data.

\section{Conclusions}

The analysis described here yielded a number of conclusions:

(1) It provided Michigan decision-makers considering future transportation funding options with information on historic conditions and the impact of previous decisions regarding funding. Results of the analysis, coupled with additional information on revenues, impact of bonding and other considerations, were summarized in Ref. [6] and distributed to decision-makers and the public;
(2) The analysis served as a useful test of MDOT's management systems that will aid in making future systems improvements. A particular issue illustrated by the analysis is that while RQFS is a powerful tool for testing future strategies, it is not designed for historic analysis or rapidly testing different budget assumptions. MDOT is now exploring the potential for coupling results from RQFS with a spreadsheet tool patterned on the analytical approach used by BCFS to leverage the strengths of both systems;

(3) The analysis demonstrated an approach for using pavement and bridge management systems to perform what-if analyses and test different funding assumptions with historic data. Pavement and bridge management systems may not be designed for such "back casting” analyses, but historic analysis can be used to help test modeling assumptions and parameters and provide insights into future decisions.

\section{References}

[1] MDOT. 2012. Highway/Bridge White Paper: 2035 MI Transportation Plan-State Long-Range Transportation Plan. MDOT. Accessed July 1, 2013. http://www.michigan.gov/documents/mdot/MDOT_High wayBridgeWhitePaperFinal_397580_7.pdf. 
[2] Galehouse, L. 2002. "Strategic Planning for Pavement Preventive Maintenance: Michigan Department of Transportation's 'Mix of Fixes' Program." MDOT. Accessed July 1, 2013. http://www.fhwa.dot.gov/pavement/preservation/ppc0302 .cfm.

[3] MDOT and Wilbur Smith and Associates. 2006. Michigan Department of Transportation State Long Range Transportation Program 2005-2030: Highway/Bridge Technical Report. MDOT.

[4] Wu, Z., Groegger, J., Simpson, A., and Hicks, R. 2010. Performance Evaluation of Various Rehabilitation and Preservation Treatments. FHWA report.

[5] FHWA. 1995. Recording and Coding Guide for the Structure Inventory and Appraisal of the Nation's Bridges. FHWA report.

[6] Gordon Proctor \& Associates, StarIsis Corp., and Spy Pond Partners, LLC. 2013. "The Road Not Taken-Michigan's Highway Funding Decisions: Lessons from the Past and Implications for the Future."
MDOT. Accessed July 2013. http://www.michigan.gov/documents/mdot/MDOT_Repo rtRoadNotTaken-5_13_13_v2_423606_7.pdf.

[7] Wong, L. 2001. "A Brief Reference on Fuel Costs and Fuel Price Elasticity.” Policy Notes 5 (1): 2.

[8] Poor, A. 2007. Fuel Price Elasticity: Synthesis. Technical report prepared for the Washington State Department of Transportation.

[9] Johnson, G., and Robert, W. 2014. "Making the Case for Asset Investment: Michigan's Use of Historic Analysis to Set the Context for Future Funding Decisions." Presented at the Transportation Research Board 10th National Conference on Transportation Asset Management, Miami, Florida.

[10] MDOT. 2000. "Road Quality Forecasting System." MDOT. Accessed July 1, 2013. http://www.michigan.gov/documents/roadquality_19998_ 7.pdf.

[11] Hearn, G. 2012. Transportation Asset Management Case Studies: Bridge Management: Practices in Idaho, Michigan, and Virginia. FHWA report. 